\title{
Characteristics and Spatial Variability of Saline-Alkaline Soil Degradation in the Typical Yellow River Delta Area of Kenli County, China
}

\author{
Zhuoran Wang, Gengxing Zhao*, Mingxiu Gao, Chunyan Chang, Jichao Jia, Jin Li \\ National Engineering Laboratory for Efficient Utilization of Soil and Fertilizer Resources, College of Resources \\ and Environment, Shandong Agricultural University, Tai'an, China \\ Email: wzr543@126.com, ${ }^{*}$ zhaogx@sdau.edu.cn
}

Received 23 July 2014; revised 15 August 2014; accepted 1 September 2014

Copyright (C) 2014 by authors and Scientific Research Publishing Inc.

This work is licensed under the Creative Commons Attribution International License (CC BY).

http://creativecommons.org/licenses/by/4.0/

(c) (i)

\section{Abstract}

As an important area of reserve land resources, the Yellow River Delta is faced with the problem of soil salinization. Grasping the characteristics of soil salinity as well as its spatial variation patterns is an important foundation of prevention, control and utilization of saline soil. This study selected Kenli County of the Yellow River Delta, obtained soil salinity data through field survey and lab experiment, and used statistical, GIS interpolation and buffer analysis methods to analyze the characteristics of soil salinity and its spatial variation patterns. Our results showed that the general soil salinity in the study area was mainly moderate and there was a significant positive correlation between different soil layers of $0-15 \mathrm{~cm}, 15-30 \mathrm{~cm}$ and $30-45 \mathrm{~cm}$ and soil salinity increased with the increase of soil depth. The areas with high soil salinity in each soil layer mainly distributed in the east near the Bo Sea in the county, while the areas with lower soil salinity mainly distributed in the southwest, centre and the two sides of the Yellow River in the northeast. Soil salinity showed a trend of decrease with the increase in distance to the Bo Sea, while stretching from the Yellow River, it showed increase tendency with the increase in distance to the Yellow River. The order from high soil salinity to low of different vegetation types was naked land $\rightarrow$ suaeda glauca $\rightarrow$ tamarix $\rightarrow$ vervain $\rightarrow$ reed $\rightarrow$ couch grass $\rightarrow$ paddy $\rightarrow$ cotton $\rightarrow$ winter wheat $\rightarrow$ maize; the order for different geomorphic types was depression $\rightarrow$ slightly sloping ground $\rightarrow$ slow hillock $\rightarrow$ high flood land. This study preliminary delineated the characteristics of soil salinity as well as its spatial variation patterns in the study area, and provided scientific basis for soil resource sustainable utilization in the Yellow River Delta.

\footnotetext{
"Corresponding author.
}

How to cite this paper: Wang, Z.R., Zhao, G.X., Gao, M.X., Chang, C.Y., Jia, J.C. and Li, J. (2014) Characteristics and Spatial Variability of Saline-Alkaline Soil Degradation in the Typical Yellow River Delta Area of Kenli County, China. Journal of Environmental Protection, 5, 1053-1063. http://dx.doi.org/10.4236/jep.2014.512104 


\section{Keywords}

\section{Kenli County, Saline-Alkaline Soil Degradation, Soil Salinity, Spatial Variation}

\section{Introduction}

At present, human are facing severe population, resources and environment crisis; saline-alkaline degradation of soil and land resources is still very serious. According to the incomplete statistics of UNESCO and FAO, the saline-alkaline land area is 99.13 million hectares in China, and they are mainly distributed in low terrain, high underwater table, semi-humid, semi-arid and arid inland or coastal areas. The Yellow River Delta is one of the fastest epeirogenic estuary deltas of China or even the world. It has rich natural resources and is the important reserve land resources in China. However, influenced by rivers, land, sea and other dynamical systems, the saline soil of the Yellow River Delta area is large with wide distribution, the land utilization changes frequently and the ecological environment is fragile. Soil salinization not only causes soil compaction and fertility decline, but also causes the loss of agricultural production, which threatens regional ecological environment and restricts the economic and social sustainable development severely. Therefore, the study of saline soil will be of great significant to the improved utilization.

Study on saline-alkaline soil degradation has always been one of the hottest topics in the study of soil science, and grasping the characteristics and spatial variability of saline soil salinity is an important foundation of soil salinization prevention, control and utilization of saline soil resources. Since 1971, FAO proposed the soil degradation problem and published the monograph of "Soil Degradation" [1], the problem has attracted increasing attention. Along with the "Global Assessment of Human-Induced Soil Degradation" (GLASOD) [2] carried out, more and more experts and scholars have conducted on the study of saline-alkaline soil degradation, especially on the characteristics and spatial variability of saline soil salinity [3]-[7]. For example, Chen Yiqun discussed the severity and dominant cause of human-induced soil degradation in the world based on World Soil Resources Report 2000 [8]; Zhang Jianfeng overviewed the status of saline-alkaline land resource of the world, analyst causes of soil salinization and put forward the basic measures to improve saline-alkaline soil resources [9]; J. Herrero studied the dynamic change of saline soil salinity over 24 years in a Mediterranean irrigated district quantitatively by collecting and analyzing samples of different years in laboratory [10]; Boško Miloš used basic geostatistical methods semivariogram-analysis to study the description and measurement spatial variability of soil properties [11]; Zhou Zaiming did research on the low plain around the Bo Sea to characterize the spatial distribution of soil salinity variables [12].

The Yellow River Delta is the concentrated saline coastal area of China and the characteristics and spatial variability of saline soil salinity has also been concerned about by the growing number of scholars [13] [14]. For example, Fan Xiaomei discussed the severity, classification and characteristics of soil salinization, described the occurring environment and influencing factors of saline soils of Yellow River Delta based on field survey and soil sampling data [15]; Yao Rongjiang used statistics and geo-statistics methods to measure and analyze spatial variability of soil salinity of different soil layers and made their spatial distribution maps [16]. But overall, the studies are still less and it is difficult to meet the current demand of efficient eco-economic development of the Yellow River Delta and the construction of "Bo Granary". This paper used field survey data in 2013 to analyze characteristics and spatial variability of saline soil salinity in typical area in the Yellow River Delta, in order to reveal the patterns. These results would provide theoretical and practical basis for improvement and utilization of soil salinization in the Yellow River Delta.

\section{Research Data and Methodology}

\subsection{Sample Collection}

Our study is conducted in Kenli County of the Yellow River Delta, which is located in the most downstream estuary of the delta. The Yellow River goes through the county into the Bo Sea from southwest to northeast. The county locates among $37^{\circ} 24^{\prime}$ to $38^{\circ} 10^{\prime}$ north latitude and $118^{\circ} 15^{\prime}$ to $119^{\circ} 19^{\prime}$ east longitude. The climate belongs to the warm temperate monsoon climate zone where winter is dry and cold, summer is hot and humid and rain- 
fall distributes uneven in time and space. The precipitation mainly concentrates in July and August and steam drop ratio is different in a year what can be as high as 7.6 during the spring. The groundwater depth is shallow with high salinity, the main soil types are salinization fluvo-aquic soil and saline soil, therefore, soil salinization is serious and the environment goes against agricultural planting and living.

In the study area, sample points were set according to land use, soil, geomorphology and vegetation types and other factors. We had set 81 sample points and got 187 groups soil salinity data, the distribution of sample points is shown in Figure 1. Soil conductivity in $0-15 \mathrm{~cm}, 15-30 \mathrm{~cm}, 30-45 \mathrm{~cm}$ soil layers were measured by EC110 portable meter, which had carried out the conductivity temperature correction. Five-point sampling method was used to collect surface soil samples, and use the handheld GPS locator to read the coordinates of each sampling point. Field survey date was from April 27 to May 1, 2013.

\subsection{Laboratory Analysis}

Dry the collected soil samples naturally in laboratory, then grinded them in order to pass over the $2 \mathrm{~mm}$ sieve. Formulated the passed soil samples into 1:5 soil water extract, oscillated 5 minutes and stood for half an hour, then used drying method to measure soil salinity content. Meanwhile, used EC110 portable meter to measure the conductivity of the soil extract, then established the relationship equation between soil extract conductivity (ECi, $\mathrm{us} / \mathrm{cm}$ ) and soil salinity content (St, \%): $\mathrm{St}=0.0004 * \mathrm{ECi}+0.0237, \mathrm{R}^{2}=0.9739$. Based on this basis, corrected field conductivity with soil extract conductivity, and established the relationship equation between field conductivity (ECo, us/cm) and soil salinity content (St, \%): St $=0.00022 *$ ECo $+0.0727, \mathrm{R}^{2}=0.9387$.

\subsection{Statistical Analysis}

Use SPSS and Excel for statistical analysis, including the analysis of descriptive statistics characteristics of soil salinity at different soil layer and their correlation, also soil salinity status of different vegetation and geomorphic types.

\subsection{Spatial Interpolation Analysis}

Use GIS software for spatial interpolation analysis and the spatial distribution map. Use ARCGIS to do the Inverse Distance Weighted (IDW) interpolation and made spatial distribution maps of soil salinity at different soil layer in Kenli County, then did description and analysis.

\subsection{Buffer Analysis}

Use the buffer analysis function of ARCGIS to build buffers of the Bo Sea and the Yellow River with radius of $15 \mathrm{~km}$ and $5 \mathrm{~km}$, and we got 6 and 14 buffers respectively. Analyze the spatial patterns of soil salinity with distance from the Bo Sea or the Yellow River. Figure 2(a) shows the distribution of the Bo Sea buffers and samples. Figure 2(b) shows the distribution of the Yellow River buffers and samples, and there are 5 buffers in the

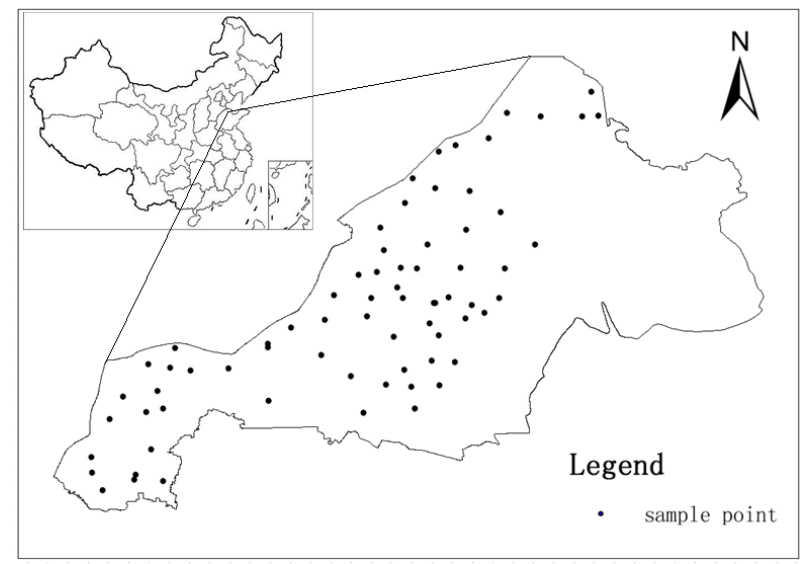

Figure 1. Study area and distribution of soil samples. 


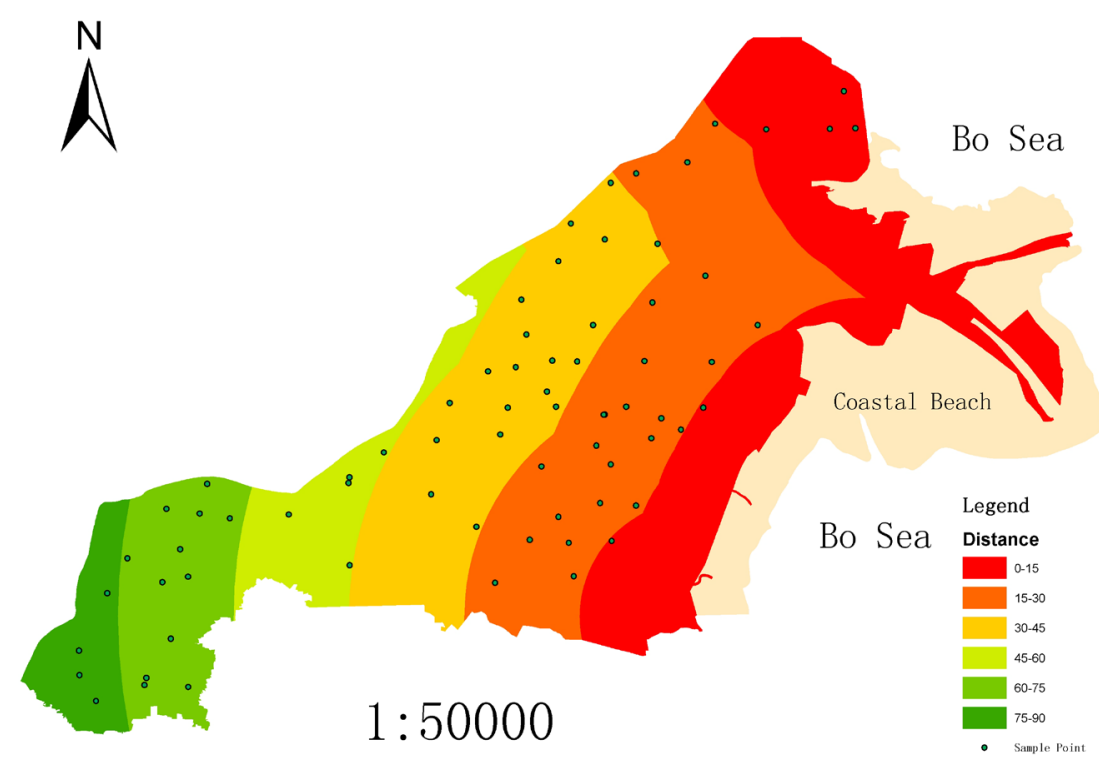

(a)

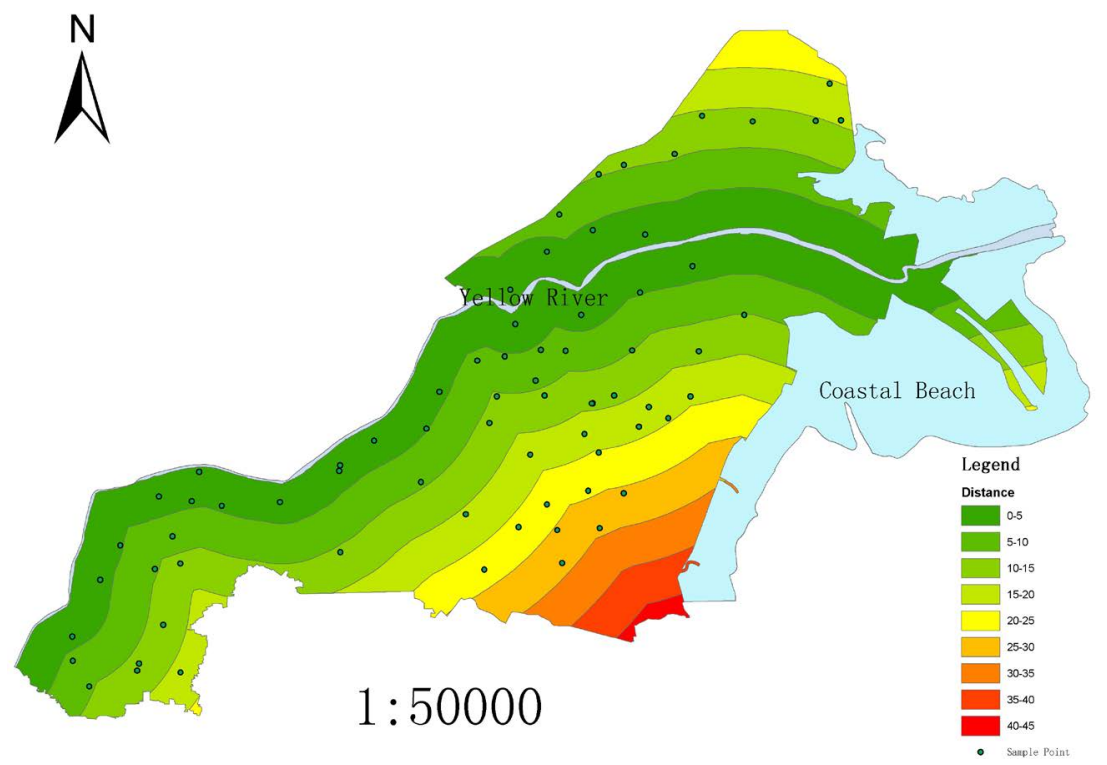

(b)

Figure 2. Bo Sea (a) and Yellow River (b) buffers distribution and sample points.

north of the Yellow River and 9 in the south.

\section{Results and Discussion}

According to related soil salinization classification standard [17], soil salinity can be divided into 5 levels in Kenli county: $<0.1 \%$ as non-salinization; $0.1 \%-0.2 \%$ as mild salinization; $0.2 \%-0.4 \%$ as moderate salinization; $0.4 \%-0.6 \%$ as severe salinization; $>0.6 \%$ as saline soil.

\subsection{Statistical Analysis of Soil salinity Status in the Study Area}

\subsubsection{Descriptive Statistical Analysis of Soil Salinity at Different Depth}

Table 1 shows the descriptive statistical characteristics of soil salinity at different depth. As can be seen, means of soil salinity in $0-15 \mathrm{~cm}, 15-30 \mathrm{~cm}, 30-45 \mathrm{~cm}$ soil layer are $0.68 \%, 0.72 \%, 0.77 \%$, medians are $0.34 \%$, 
$0.47 \%, 0.54 \%$, and all of them show rising trends from the surface to the bottom. Also, means are greater than medians, indicating that soil salinity is a left excursion distribution; therefore, the median is suitable for describing the overall soil salinity level in Kenli County. The county belongs to the moderate salinization degree in 0 $15 \mathrm{~cm}$ soil layer and severe salinization in both $15-30 \mathrm{~cm}$ and $30-45 \mathrm{~m}$ soil layers.

From the point of variation, maximums of soil salinity at different soil layers are 38.78 times, 31.38 times, 27.57 times than their minimums, changes are $4.49 \%$, 3.95\%, 3.72\%, and coefficients of variation are $1.28,0.99$, and 0.95. According to the division level of the coefficient of variation: $\mathrm{CV}<0.1$ as weak variability, $0.1<\mathrm{CV}$ $<1$ as moderate variability, CV $>1$ as the strong variability, then soil salinity at different soil layers all belong or nearly belong to strong variability. Then, there are strong degrees of variability in horizontal direction of soil salinity in $0-15 \mathrm{~cm}, 15-30 \mathrm{~cm}, 30-45 \mathrm{~cm}$ soil layers. With the increase of soil depth, all of the maximum and minimum ratios, the changes and the coefficients of variation decrease, which show that variability of soil salinity in each soil layer are gradually weakening with the increase of soil depth.

\subsubsection{Correlation Analysis of Soil Salinity between Different Depths}

Table 2 shows the correlation coefficient of soil salinity between different depths. As can be seen, the correlation coefficients between two different soil layers are all greater than 0.84 , which shows significant positive correlation. The correlation coefficient of soil salinity between $30-45 \mathrm{~cm}$ soil layer and $15-30 \mathrm{~cm}(0.9131)$ is greater than it between $15-30 \mathrm{~cm}$ and $0-15 \mathrm{~cm}(0.8954)$. It shows that the correlation of adjacent layers increases gradually with the increase of soil depth, and the influence between adjacent soil layers is greater than alternate soil layers.

\subsection{Spatial Distribution Analysis}

\subsubsection{Spatial Distribution of Soil Salinity}

Figures 3(a)-(c) are the spatial distribution of soil salinity in $0-15 \mathrm{~cm}, 15-30 \mathrm{~cm}, 30-45 \mathrm{~cm}$ soil layers in Kenli County. As can be seen, there are obvious patterns from west to east between the distribution of soil salinity and the distance from the Bo Sea. The areas with high soil salinity in each soil layer distributes mainly in the east and southeast coast of the county, while the areas with lower soil salinity in southwest, centre and the northeastern part of the Yellow River, where is far from the Bo Sea. Salinization of each soil layer shows a worsening trend from west to east.

\subsubsection{Spatial Distribution Statistics of Soil Salinity at Different Depths}

Table 3 shows the area ratios of spatial distribution of soil salinity at different depths. As can be seen, the area ratios of mild salinization in each soil layer are least which are all less than $1 \%$, while saline soil the largest with more than $40 \%$. From $0-15 \mathrm{~cm}$ to $30-45 \mathrm{~cm}$ soil layer, the area ratios of moderate salinization gradually decreases from $38.86 \%$ to $12.58 \%$, while the severe salinization increases from $19.70 \%$ to $35.54 \%$ and the saline

Table 1. Descriptive statistics characteristics of soil salinity at different depths.

\begin{tabular}{cccccccc}
\hline Soil depth (cm) & Amount & Mean & Median & Standard deviation & Min & Max & Coefficient of variation \\
\hline $0-15$ & 187 & 0.68 & 0.34 & 0.88 & 0.11 & 4.27 & 1.28 \\
$15-30$ & 187 & 0.72 & 0.47 & 0.71 & 0.15 & 4.08 & 0.99 \\
$30-45$ & 187 & 0.77 & 0.54 & 0.73 & 0.14 & 3.86 & 0.95 \\
\hline
\end{tabular}

Table 2. Correlation coefficient of soil salinity between different depths.

\begin{tabular}{ccc}
\hline Soil depth $(\mathbf{c m})$ & $\mathbf{0}-\mathbf{1 5}$ & $\mathbf{1 5}-\mathbf{3 0}-\mathbf{4 5}$ \\
\hline $0-15$ & 1.0000 & 1.0000 \\
$15-30$ & $0.8954^{* *}$ & $0.9131^{* *}$ \\
$30-45$ & $0.8466^{* *}$ & 1.0000 \\
\hline
\end{tabular}

Note: ${ }^{* *}$ Indicates a significant level of $\mathrm{p}<0.01$. 


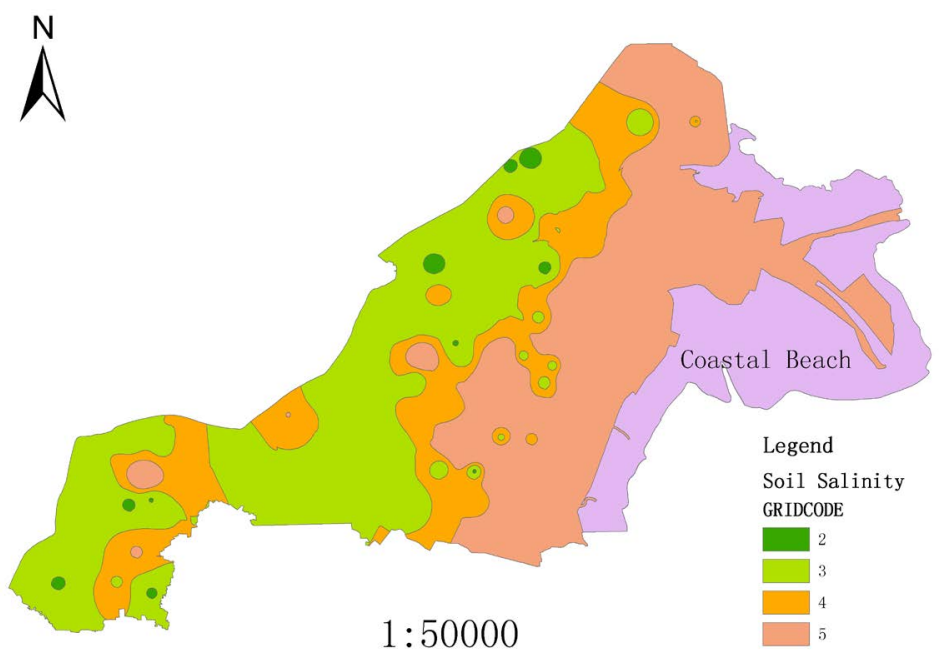

(a)

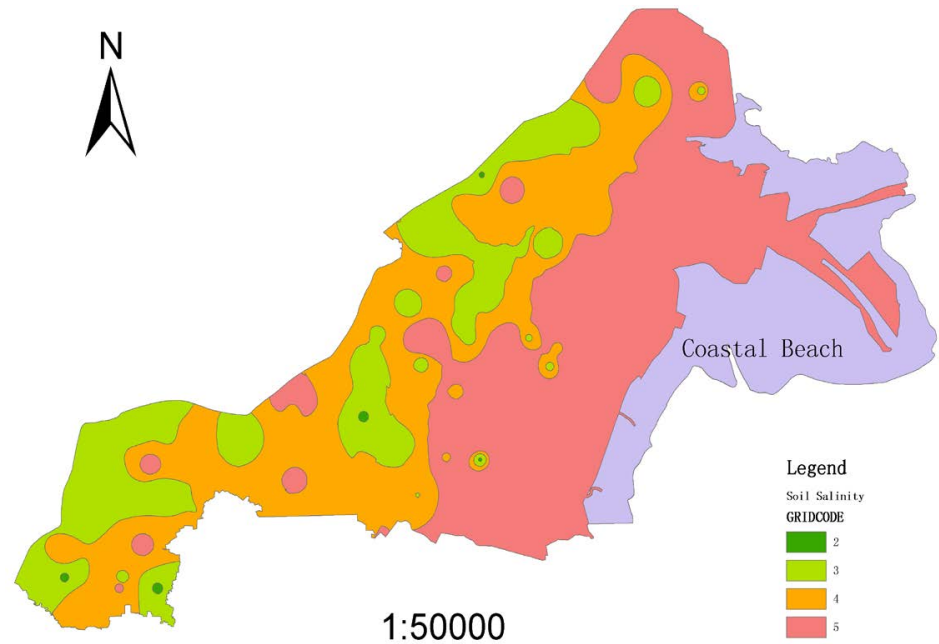

(b)

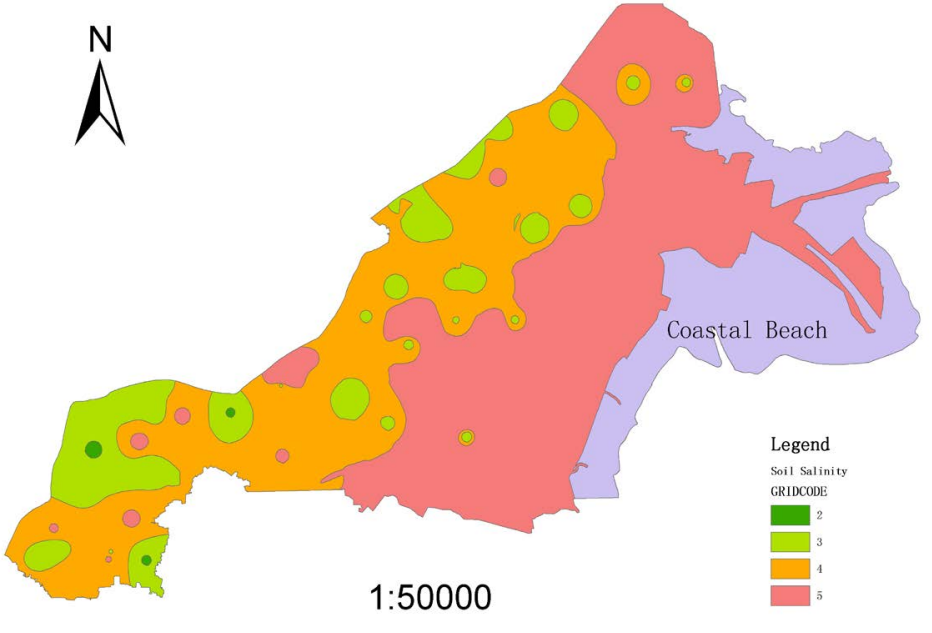

(c)

Figure 3. Spatial distribution of soil salinity at different depths in Kenli County. (a) 0 - $15 \mathrm{~cm}$ soil layer; (b) 15 - $30 \mathrm{~cm}$ soil layer; (c) 30 - $45 \mathrm{~cm}$ soil layer. 
Table 3. Area ratios of spatial distribution of soil salinity at different depths.

\begin{tabular}{ccccc}
\hline Soil salinity (\%) & Soil salinization & \multicolumn{3}{c}{ Area ratio (\%) } \\
\cline { 3 - 5 } & & $\mathbf{0}-\mathbf{1 5} \mathbf{~ c m}$ & $\mathbf{1 5} \mathbf{- 3 0} \mathbf{~ c m}$ & $\mathbf{3 0}-\mathbf{4 5} \mathbf{~ c m}$ \\
\hline$<0.1$ & Non-salinization & 0.00 & 0.00 & 0.00 \\
$0.1-0.2$ & Mild salinization & 0.75 & 0.14 & 0.20 \\
$0.2-0.4$ & Moderate salinization & 38.86 & 20.21 & 12.58 \\
$0.4-0.6$ & Severe salinization & 19.70 & 33.42 & 35.54 \\
$>0.6$ & Saline soil & 40.69 & 46.23 & 51.68 \\
\hline
\end{tabular}

soil from $40.59 \%$ to $51.68 \%$. It indicates that with the increase of soil depth, moderate salinization areas decrease gradually, severe salinization and saline soil increases, the overall degree of soil salinization increases gradually.

\subsection{Spatial Variation of Soil Salinity}

\subsubsection{Spatial Variation of Soil Salinity from the Yellow River to the Bo Sea}

Figure 4 shows the typical distribution of soil samples (069-070-047-049-026-017-014) from the Yellow River to the Bo Sea which lying nearly like a line. As can be seen, soil salinity increases significantly from $0.12 \%$ of no.069 near the Yellow River to 3.15\% of no.014 near the Bo Sea, soil salinization also increases from mild to moderate to severe and saline gradually. It illustrates that soil salinity shows a rising trend with further away from the Yellow River or going close to the Bo Sea.

\subsubsection{Spatial Variation of Soil Salinity in Bo Sea Buffers}

Table 4 shows statistics characteristics of soil salinity in Bo Sea buffers. As can be seen, with further away from the Bo Sea, soil salinity decreases from $2.31 \%$ to $0.30 \%$, despite the rise in the middle $(0.43 \%)$, there is still a downward trend overall, and soil salinization decreases from saline to severe and moderate salinization. It shows that with further away from the Bo Sea, soil salinity gets a decreasing trend.

\subsubsection{Spatial Variation of Soil Salinity in Yellow River Buffer}

Table 5 shows statistics characteristics of soil salinity in Yellow River buffers. As can be seen, with the increase in distance from the Yellow River in the north buffers, soil salinity decreases slowly from $0.29 \%$ to $0.22 \%$, then jumps to $3.09 \%$, which rises significantly. In the south buffers, soil salinity increases gradually from $0.35 \%$ to 0.65\%, when it reaches to no.6 buffer which is near the Bo Sea and over $25 \mathrm{~km}$ away from the Yellow River, soil salinity jumps to $1.35 \%$. In general, stretching from the Yellow River, soil salinity shows increase tendency with the increase in distance from the Yellow River. It reflects the significant influence on soil salinity by the Yellow River fresh water around.

\subsection{Soil Salinity Status of Different Vegetation Types}

Table 6 shows statistics characteristics of soil salinity of different vegetation types. As can be seen, there are clear difference of soil salinity among different vegetation types. The order from high saltness to low of different vegetation types is naked land $\rightarrow$ suaeda glauca $\rightarrow$ tamarix $\rightarrow$ vervain $\rightarrow$ reed $\rightarrow$ couch grass $\rightarrow$ paddy $\rightarrow$ cotton $\rightarrow$ winter wheat $\rightarrow$ maize. Soil salinity of naked land is the greatest and the level of salification in naked land is the most intensive. Salt content of soil covered with vegetation decreases significantly. In uncultivated land, salinity means of soil growth of Suaeda glauca and Tamarix are $2.38 \%$ and $1.55 \%$ and they are apparently higher than soil growth of vervain $(0.64 \%)$, reed $(0.63 \%)$ and couch grass $(0.46 \%)$, which shows the possibility to be indicator plants of saline soil. In crops, soil salinity in paddy fields is the highest, mean is $0.35 \%$ and range is $0.23 \%-0.49 \%$, showing paddy fields generally chose lands with high salt content and not suitable for dry farming. Mean of soil salinity in cotton fields is $0.32 \%$, range is $0.11 \%-0.93 \%$, and there are 27 samples with salt content less than $0.2 \%$ belonging to mild salinization. It also suggests the feasibility of adjusting the cotton 


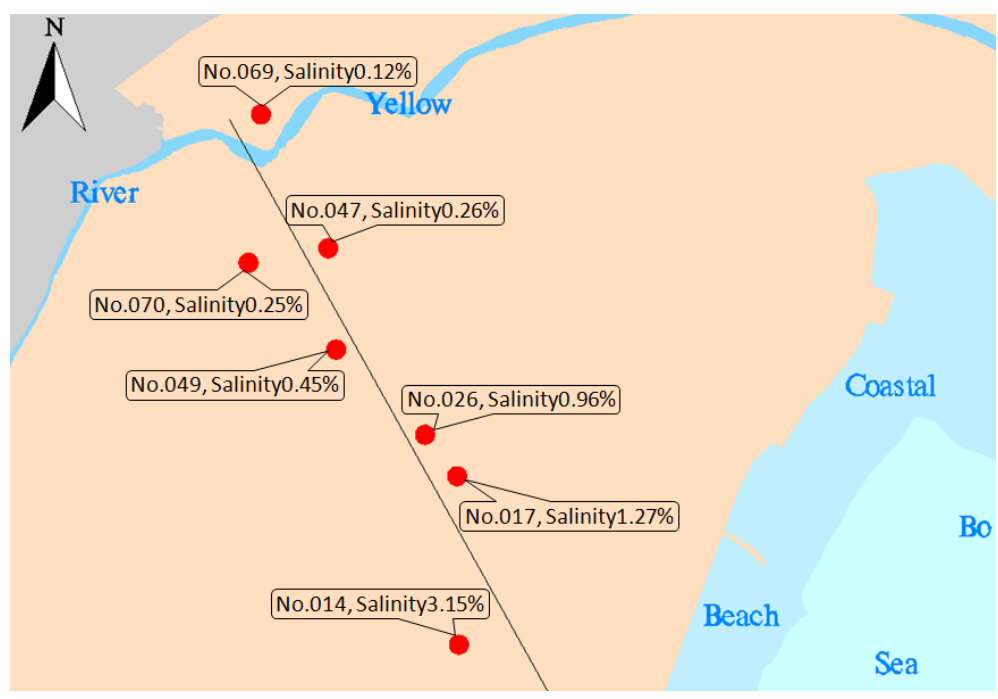

Figure 4. Typical distribution of soil samples and their soil salinity data from the Yellow River to the Bo Sea.

Table 4. Statistics characteristics of soil salinity in Bo Sea buffers.

\begin{tabular}{cccc}
\hline Buffer number & Distance from Bo Sea $(\mathbf{k m})$ & Amount & Soil salinity (\%) \\
\hline 1 & $0-15$ & 17 & 2.31 \\
2 & $15-30$ & 58 & 0.73 \\
3 & $30-45$ & 52 & 0.36 \\
4 & $45-60$ & 13 & 0.35 \\
5 & $60-75$ & 32 & 0.43 \\
\hline
\end{tabular}

Table 5. Statistics characteristics of soil salinity in Yellow River buffer.

\begin{tabular}{ccccc}
\hline Area & Buffer number & Distance from the river $\mathbf{( k m )}$ & Amount & Soil salinity (\%) \\
\hline & 1 & $0-5$ & 13 & 0.29 \\
\multirow{3}{*}{ North } & 5 & $5-10$ & 3 & 0.22 \\
& 3 & $10-15$ & 11 & 0.32 \\
& 4 & $15-20$ & 7 & 3.09 \\
\hline & 1 & $0-5$ & 50 & 0.35 \\
& 2 & $5-10$ & 38 & 0.48 \\
& 3 & $10-15$ & 26 & 0.61 \\
& 4 & $15-20$ & 18 & 0.63 \\
& & $20-25$ & 12 & 0.65 \\
\hline
\end{tabular}

fields to crops. Mean of soil salinity in winter wheat field is $0.29 \%$ and range is $0.18 \%-0.42 \%$. Meanwhile, soil salinity in corn fields is the least, range is $0.13 \%-0.34 \%$ and mean is $0.24 \%$.

It can be discovered from the field survey that soil salinity is the main limiting factor of spatial distribution of 
Table 6. Statistics characteristics of soil salinity of different vegetation types.

\begin{tabular}{ccccc}
\hline Vegetation types & Amount & \multicolumn{3}{c}{ Soil salinity (\%) } \\
\cline { 3 - 5 } Maize & 8 & Mean & Min & Max \\
Winter wheat & 14 & 0.24 & 0.13 & 0.34 \\
Cotton & 91 & 0.29 & 0.18 & 0.42 \\
Paddy & 14 & 0.32 & 0.11 & 0.93 \\
Couch grass & 9 & 0.35 & 0.23 & 0.79 \\
Reed & 19 & 0.46 & 0.19 & 1.56 \\
Vervain & 6 & 0.63 & 0.19 & 0.73 \\
Tamarix & 6 & 0.64 & 0.55 & 2.32 \\
Suaeda glauca & 12 & 1.55 & 1.20 & 4.92 \\
Naked land & 8 & 2.38 & 1.13 & 4.68 \\
\hline
\end{tabular}

vegetation in Kenli County. Salt tolerant plants such as suaeda glauca and tamarix mainly are grown in the areas with higher soil salinity, where the terrain is low and is near the Bo Sea. Going far away from the Bo Sea, with the hypsography run-up and being close to the Yellow River, soil salinity decreases gradually and certain salt tolerant plants such as vervain, reed and couch grass are grown in these areas. Winter wheat or corn are planted on contiguous fields where are further away from the Bo Sea and along the Yellow River with less soil salinity. Cotton what is relatively salt tolerant is grown in fields with high soil salinity, while paddy is grown in small amount fields where can guarantee irrigation. Therefore, better economic benefit can be obtained if adjusting the crop planting structure reasonably according to the soil salinity status.

\subsection{Soil Salinity Status of Different Geomorphic Types}

Table 7 shows the area ratios and statistics characteristics of soil salinity of different geomorphic types. As can be seen, there are clear difference of soil salinity among them. Depression mainly distributes in the central of the county and the area ratio is $7.55 \%$. Due to low terrain and shallow groundwater table, soil salinity is high and mean is $0.71 \%$, soil salinization is serious. Slightly sloping ground is the main geomorphic type with an area ratio of $67.09 \%$ and mean of soil salinity is $0.62 \%$. Because of widely distribution and influenced by natural and artificial multiple factors, soil salinization is unevenly distributed. Slow hillock mainly distributes in southwestern in the county, but with an area ratio of only $2.7 \%$. Mean of soil salinity is $0.38 \%$ and soil salinization degree is relatively light. High flood land mainly distributes in the old and new Yellow River coasts with an area ratio of $22.66 \%$. Because of proximity of the Yellow River and high altitude, soil salinity is the least which is $0.33 \%$.

\subsection{Discussion}

The unique surface water and groundwater, topography, soil types and other conditions in the Yellow River Delta determine the activity of soil salt movement in the area. Under the influence of different climate, location, and tillage management, the soil salinity status shows out not only spatial variability, but also greater temporal variability. This paper only studied the status of soil salinity in spring (April-May), further research on soil salinity conditions in different seasons such as summer, autumn or winter in the area, as well as spatial and temporal variability among seasons will follow.

\section{Conclusions}

1) Soil salinity in the study area is generally high; it is mainly moderate salinization and shows strong variability. The areas with high soil salinity in $0-15 \mathrm{~cm}, 15-30 \mathrm{~cm}$ and $30-45 \mathrm{~cm}$ soil layers mainly distribute in the east near the Bo Sea in Kenli County, while the areas with lower soil salinity mainly distribute in the 
Table 7. Area ratios and statistics characteristics of soil salinity of different geomorphic types.

\begin{tabular}{|ccccccc}
\hline Geomorphic types & Area ratio (\%) & Amount & & \multicolumn{3}{c}{ Soil salinity (\%) } \\
\cline { 5 - 7 } & & & Mean & Min & Max \\
\hline Depression & 7.55 & 24 & 0.71 & 0.14 & 2.32 \\
Slightly sloping ground & 67.09 & 107 & 0.62 & 0.13 & 4.92 \\
Slow hillock & 2.7 & 7 & 0.38 & 0.26 & 0.62 \\
High flood land & 22.66 & 49 & 0.33 & 0.11 & 0.93 \\
\hline
\end{tabular}

southwest, centre and the two sides of the Yellow River in the northeast. There are significant positive correlations between different soil layers and soil salinity shows an increase trend with the increase of soil depth. This result reflects that the coastal saline soil has the characteristics of entire high salinity and serious salinization.

2) Soil salinity shows a trend of decrease with the increase in distance to Bo Sea. When stretching from the Yellow River, soil salinity shows an increase tendency with the increase in distance to the Yellow River. It illustrates that spatial patterns of soil salinity in the study area is highly impacted by the Yellow River and the Bo Sea and it is the result of the interaction of the Yellow River freshwater and high mineralization saltwater.

3) There are significant relationships between soil salinity and different vegetation types or geomorphic types. The order from high soil salinity to low of different vegetation types is naked land $\rightarrow$ suaeda glauca $\rightarrow$ tamarix $\rightarrow$ vervain $\rightarrow$ reed $\rightarrow$ couch grass $\rightarrow$ paddy $\rightarrow$ cotton $\rightarrow$ winter wheat $\rightarrow$ maize; the order of different geomorphic types is depression $\rightarrow$ slightly sloping ground $\rightarrow$ slow hillock $\rightarrow$ high flood land. On one hand, it indicates that soils in different salinity environment corresponding to different suitable plants show the interaction of soilvegetation system, which has been associated with other same results [18]-[20]. On the other hand, it provides the possibility to estimate soil salinization status indirectly through vegetation or geomorphic types.

\section{Acknowledgements}

This study was supported by the "Twelfth Five Year" National Science and Technology Support Project (2013BAD05B06), the National Natural Science Foundation of China (41271235) and the Shandong Independent Innovation Fund (2012CX90202). We gratefully acknowledge support from College of Resources and Environment of Shandong Agricultural University and National Engineering Laboratory for Efficient Utilization of Soil and Fertilizer Resources.

\section{References}

[1] Lal, R. and Steward, B.A. (1990) Soil Degradation. Springer-Verlag Inc., New York.

[2] Oldeman, L.R. (1988) Guidlines for Global Assessment of the Status of Human-Induced Soil Degradation. GLASOD.

[3] Raina, P., Joshi, D.C. and Kolarkar, A.S. (1993) Mapping of Soil Degradation by Using Remote Sensing on Alluvial plain, Rajasthan, India. Arid Land Research and Management, 7, 145-161.

[4] Lobell, D.B. (2010) Remote Sensing of Soil Degradation: Introduction. Journal of Environmental Quality, 39, 1-4. http://dx.doi.org/10.2134/jeq2009.0326

[5] Oldeman, L.R. (1994) The Global Extent of Soil Degradation. In: Greenland, D.J. and Szabolcs, I., Eds., Soil Resilience and Sustainable Landuse, CAB International, Wallingford, 99-119.

[6] Burgess, T.M. and Webster, R. (1980) Optimal Interpolation and Isarithmic Mapping of Soil Properties. Soil Science, 31, 315-341. http://dx.doi.org/10.1111/j.1365-2389.1980.tb02084.x

[7] Yemefack, M., Rossiter, D.G. and Njomgang, R. (2005) Multi-Scale Characterization of Soil Variability within an Agricultural Landscape Mosaic System in Southern Cameroon. Geoderma, 125, 117-143. http://dx.doi.org/10.1016/j.geoderma.2004.07.007

[8] Chen, Y.Q., Dong, Y.H. and Chen, D.Q. (2008) Driving Force for Human-Induced Soil Degradation. Transactions of the CSAE, 24, 114-118.

[9] Zhang, J.F., Zhang, X.D., Zhou, J.X., et al. (2005) World Resources of Saline Soil and Main Amelioration Measures. Research of Soil and Water Conservation, 12, 28-30. 
[10] Herrero, J. and Pérez-Coveta, O. (2004) Soil Salinity Changes over 24 Years in a Mediterranean Irrigated District. Geoderma, 125, 287-308.

[11] Miloš, B. (2000) Geostatistical Soil Data Analysis I. Measuring Spatial Variability of Soil Properties with Semivariograms. Agriculturae Conspectus Scientificus, 65, 219-228.

[12] Zhou, Z., Zhang, G., Wang, J. and Yan, M.J. (2010) Spatial Pattern of Soil Salinity and Soil Salinization in Area around Bo Sea. Transactions of the CSAE, 26, 15-20.

[13] Qin, Y. and Zhao, G. (2009) Restoration and Reutilization Evaluation of Coastal Saline-Alkaline Degraded lands in Yellow River Delta. Transactions of the CSAE, 25, 306-311.

[14] Lv, Z.Z., Liu, G.M., Yang, J.S., Zhang, M.M., He, L.D., Shao, H.B., et al. (2013) Spatial Variability of Soil Salinity in Bohai Sea Coastal Wetlands, China: Partition into Four Management Zones. Plant Biosystems, 147, 1201-1210.

[15] Fan, X., Liu, G., Tang, Z. and Shu, L.C. (2010) Analysis on Main Contributors Influencing Soil Salinization of Yellow River Delta. Journal of Soil and Water Conservation, 24, 139-144.

[16] Yao, R., Yang, J., Liu, G. and Zou, P. (2006) Spatial Variability of Soil Salinity in Characteristic Field of the Yellow River Delta. Transactions of the CSAE, 22, 61-66.

[17] Bao, S. (2000) Soil and Agricultural Chemistry Analysis. China Agriculture Press China Agriculture Press, Beijing, $178-200$.

[18] Wang, H., Li, Z., Song, G., Gao, J. and Yan, J. (2006) The Correlation among Vegetation Distribution, Land Use Type and Soil Character in Yellow River Delta. Acta Scientiarum Naturalium Universitatis NeiMongol, 37, 69-75.

[19] Ma, Y., Wang, D., Liu, J., Wen, X.H., Gao, M. and Shao, H.B. (2013) Relationships between Typical Vegetations, Soil Salinity, and Groundwater Depth in the Yellow River Delta of China. Chinese Journal of Applied Ecology, 24, 24232430.

[20] Wu, Z., Zhan, S. and Zhang, X. (1994) Studies on Interrelation between Salt Vegetation and Soil Salinity in the Yellow River Delta. Acta Phytoecologica Sinica, 18, 184-193. 
Scientific Research Publishing (SCIRP) is one of the largest Open Access journal publishers. It is currently publishing more than 200 open access, online, peer-reviewed journals covering a wide range of academic disciplines. SCIRP serves the worldwide academic communities and contributes to the progress and application of science with its publication.

Other selected journals from SCIRP are listed as below. Submit your manuscript to us via either submit@scirp.org or Online Submission Portal.
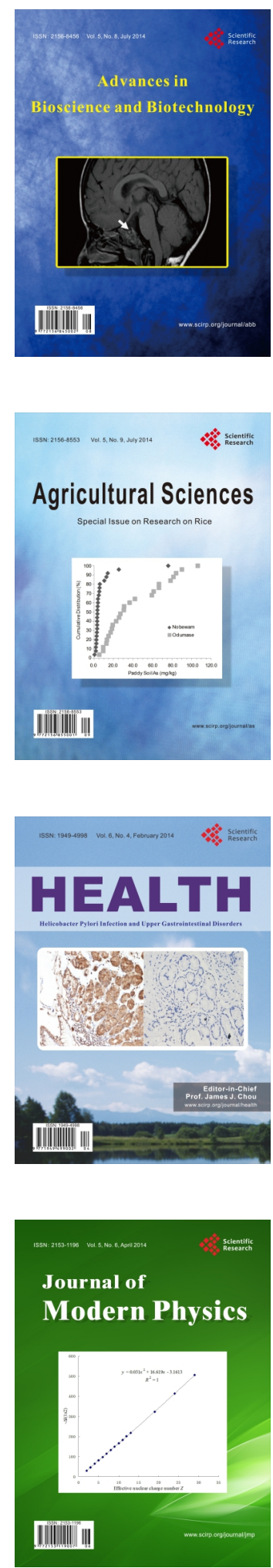
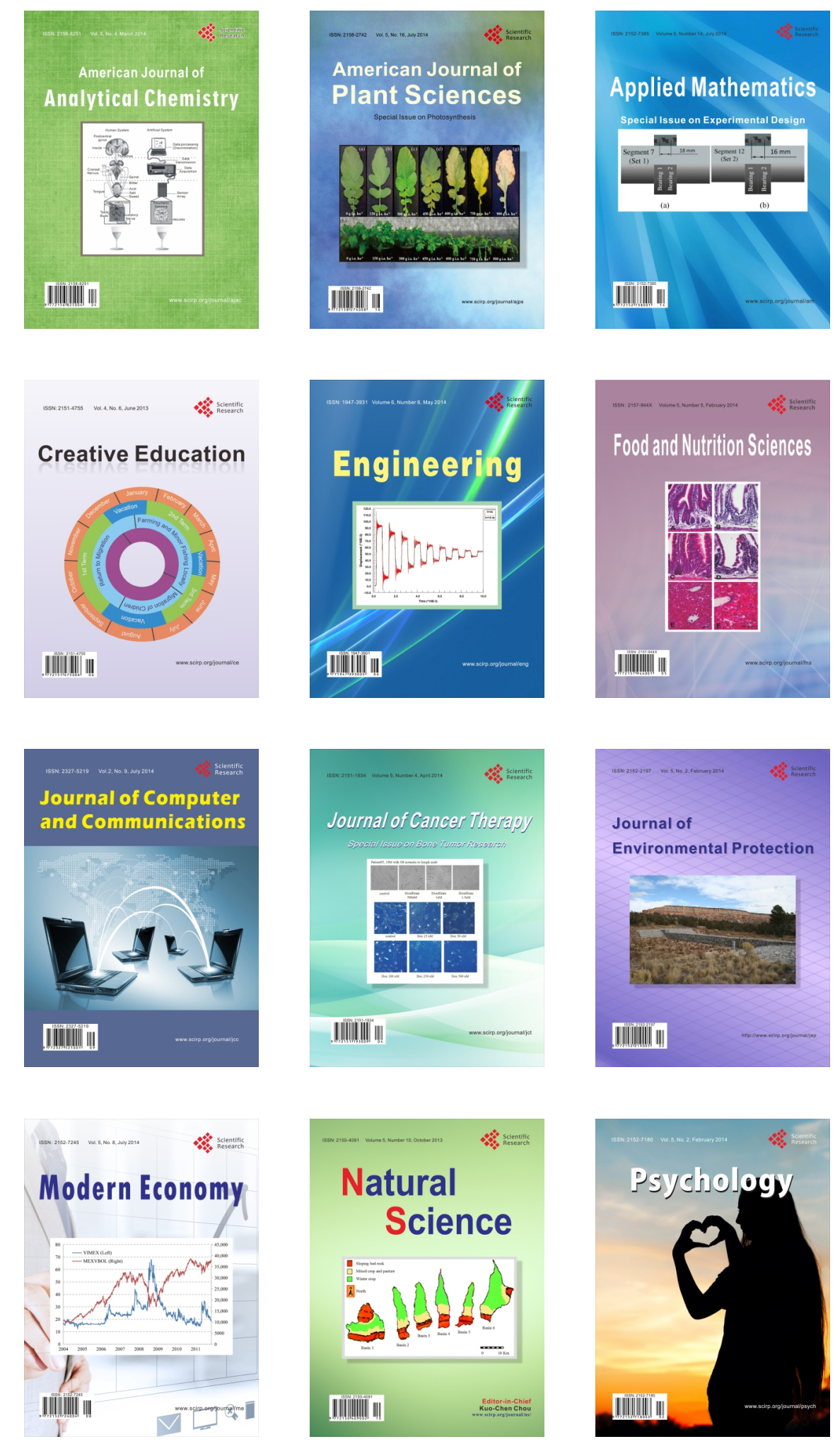